\title{
Heterogeneity in Alzheimer's disease: progression rate segregated by distinct neuropsychological and cerebral metabolic profiles
}

\author{
Ulrike M Mann, Erich Mohr, Margaret Gearing, Thomas N Chase
}

\begin{abstract}
In an attempt to define possible subgroups of Alzheimer's disease, 21 patients satisfying current clinical diagnostic criteria for this disorder were divided on the basis of progression rates of symptoms. Thirteen patients with relatively rapid intellectual deterioration did not differ from eight patients showing slow progression with respect to global intellectual performance, sex, or age at onset of symptoms. Neuropsychological testing revealed that although the two groups were indistinguishable in verbal or visuospatial functions associated with the parietotemporal cortex, the more rapidly deteriorating group had significantly greater impairment in executive functions attributed to the frontal lobe. PET scans showed equivalent reductions in glucose metabolism in the parietotemporal cortex, but patients with relatively fast progression had significantly greater hypometabolism frontally. These results suggest an association between relatively severe frontal lobe involvement and a rapid clinical course that might have important implications for the development of treatment strategies for patients with Alzheimer's disease.
\end{abstract}

(F Neurol Neurosurg Psychiatry 1992;55:956-959)

Alzheimer's disease, characterised clinically by progressive cognitive deterioration, does not fit a uniform pattern. ${ }^{12}$ Indeed, the disorder has been subgrouped on the basis of age at onset, ${ }^{34}$ on morphological or neurochemical grounds, ${ }^{56}$ and on neuropsychological or cerebral imaging profiles. ${ }^{78}$ Distinct deficits in visuospatial or verbally mediated domains ${ }^{79}$ as well as in specific memory function ${ }^{10}$ have been applied to the categorisation of Alzheimer's patients. Positron emission tomography (PET) studies have shown that although regional glucose metabolism is characteristically reduced in the parietotemporal cortex, ${ }^{11}{ }^{12}$ portions of the frontal lobes may also be substantially affected in some patients. ${ }^{1314}$

The rate of symptom progression in Alzheimer's disease has long been known to vary widely, with illness ranging from only a few months' duration to as long as 21 years. ${ }^{15}{ }^{16} \mathrm{We}$ have previously described neuropsychological differences between slowly and rapidly deteri- orating patients: whereas slowly deteriorating patients showed a predominantly posterior pattern of cognitive impairment, faster declining patients showed an additional defect in tests associated with frontal lobe function. ${ }^{17} \mathrm{To}$ evaluate a possible relation between the pace of cognitive deterioration and the distribution of cortical dysfunction we examined regional cerebral metabolism as revealed by PET scans after [18F]-fluorodeoxyglucose was given to a group of Alzheimer patients who had received extensive neuropsychological testing.

\section{Patients and methods}

Patients included in this study were evaluated in the dementia clinic of the Experimental Therapeutics Branch at the National Institutes of Health between 1986 and 1989 and were found to satisfy DSM III-R criteria for primary degenerative dementia ${ }^{18}$ and NINCDSADRDA criteria for probable Alzheimer's disease. ${ }^{19}$ Among 41 patients who had received extensive neuropsychological testing in preparation for possible inclusion in various clinical studies, ${ }^{17} 21$ (12 men, 9 women; mean (SE) age $67(1 \cdot 8)$ years, range 55-82 years) were found to have been further assessed by PETfluorodeoxyglucose scanning. None of these subjects had intercurrent medical illness or were receiving centrally active drugs at the time of testing. All had provided informed consent after full disclosure of the potential risks and benefits of this study.

An index of disease progression was calculated for each individual as:

$$
\frac{140 \text { - DRS score }}{\text { symptom duration }}
$$

where 140 was considered the lowest "normal" score on the dementia rating scale (DRS), ${ }^{20}$ DRS score was the patient's current level of performance, and symptom duration was based on the patient's records and information provided by family members. ${ }^{17}$ Subjects were then divided into a slowly progressive group, which included all those with an index below the midpoint of the entire range of values, and a rapidly progressive group, comprising those with an index higher than the midpoint.

General intellectual function and memory function were assessed with the Wechsler adult intelligence scale-revised (WAIS-R) ${ }^{21}$ and the Wechsler memory scale (WMS). ${ }^{22}$ In addition, 
the following domain specific neurpsychological tests were used: Rey verbal learning ${ }^{23}$ and sentence memory ${ }^{24}$ to evaluate verbal cognitive function; Rey Osterrieth complex figure, ${ }^{2526}$ Benton visual retention test, ${ }^{27}$ street map, ${ }^{28}$ and mosaics ${ }^{29}$ to measure visuospatial performance; word fluency ${ }^{30}$ and a modified version of the ego state inventory ${ }^{31}$ as tests of executive function.

PET scans were performed with subjects lying in a quiet, darkened room with eyes covered and ears plugged. After an intravenous bolus injection of $5 \mathrm{mCi}$ [18F] 2-fluoro2-deoxy-D-glucose (FDG), serial blood samples were taken from an "arterialised" peripheral vein (local warming to $44^{\circ} \mathrm{C}$ with a heating pad) contralateral to the side of injection. Thirty minutes later, scanning was begun with the NeuroPET, a seven slice tomograph with a spatial resolution of approximately $6 \mathrm{~mm}$ (full width at half maximum) in the image plane and $11.5 \mathrm{~mm}$ slice thickness. Fourteen to 42 slices parallel to the canthomeatal line were obtained. Images were reconstructed and local metabolic rates for glucose calculated. ${ }^{32}$ Image analysis was performed on seven equally spaced levels using LISPIX, a processing system composed of a FORTRAN library drive by LISP. ${ }^{33}$ After shape normalisation, glucose values were obtained from 224 contiguous cortical and subcortical regions. Values were normalised by calculating the ratio of each region to white matter. Data were averaged for the following regions: inferior, middle, superior anterior, superior mesial, and superior posterior frontal cortex; inferior and superior temporal cortex; inferior and superior parietal cortex; occipital cortex, caudate and lenticular nuclei, and thalamus. To determine the degree of regional differences between patient groups, an index:

$$
\frac{(\mathrm{rGMR})_{S}-(\mathrm{rGMR})_{\mathrm{R}}}{\left((\mathrm{rGMR})_{S}+(\mathrm{rGMR})_{\mathrm{R}} / 2\right)}
$$

was calculated, where $(\mathrm{rGMR})_{\mathrm{S}}$ represents the regional glucose metabolic rate (rGMR) of the slowly progressive group and $(r G M R)_{R}$ the rate of the rapidly progressive group.

Data were analysed with analysis of variance procedures and with Pearson's correlation. ${ }^{34}$

\section{Results}

Symptom progression indices ranged from 1.8 to 28.0 for the average annual decline in dementia rating scale scores. Thirteen patients had progression indices below the midpoint of this range and were considered slow progressors; eight had indices above the midpoint and were considered rapid progressors. There were no significant differences between these two groups with respect to age at symptom onset, age at time of testing, or educational level. The groups differed only with respect to the duration of their symptoms and their dementia rating scale scores, factors that contributed to the progression index (table 1).

Neuropsychological evaluation revealed comparable scores for both groups in tests of
Table 1 Clinical characteristics of patients with slow and rapid progression of Alzheimer's disease. Values are mean (SE) unless otherwise indicated

\begin{tabular}{lll}
\hline & $\begin{array}{l}\text { Slow } \\
\text { progression } \\
(n=13)\end{array}$ & $\begin{array}{l}\text { Rapid } \\
\text { progression } \\
(n=8)\end{array}$ \\
\hline Sex $(\mathrm{M}: \mathrm{F})$ & $7: 6$ & $5: 3$ \\
Age at disease onset & $64(2 \cdot 3)$ & $61(2 \cdot 6)$ \\
Age at testing & $69(2 \cdot 3)$ & $63(2 \cdot 8)$ \\
Education & $17(1 \cdot 0)$ & $16(1 \cdot 0)$ \\
Symptom duration & $5(0 \cdot 8)$ & $2(0 \cdot 4)^{\star}$ \\
Mattis & $114(2 \cdot 7)$ & $94(11)^{\star}$ \\
Progression index & $6 \cdot 8(0 \cdot 9)$ & $22(1 \cdot 8)^{\star \star}$ \\
\hline
\end{tabular}

Progression index was derived as 140 - DRS scores / symptom duration.

${ }^{\star} \mathrm{p}<0.05$ for group differences.

${ }^{\star} \mathrm{p}<0.0001$ for group differences.

global intellectual performance and memory performance (WAIS-R, WMS) as well as in specific tests of verbal and visuospatial function. Neuropsychological tasks involving executive function, on the other hand, yielded significantly lower scores for the more rapidly deteriorating group ( $<<0.05$; table 2$)$. Moreover, only performance on tests of executive function correlated significantly with patients' progression indices (table 3 ).

Positron emission tomography failed to show any group difference in regional cerebral metabolism in temporal, parietal, or occipital cortices, nor in any of the subcortical nuclei analysed (table 4). In contrast, cortical metabolic values in the mesial and posterior regions of the superior frontal lobe bilaterally (Brodman area 6 to 9) were significantly lower in the rapidly progressive group (table 4). Linear correlation analysis of the regional metabolic values with the progression indices revealed a significant decrease in metabolism with increasing rates of deterioration only in the superior frontal cortex (table 5). No systematic differences were found between the left and right hemisphere. Regarding the degree of regional differences between groups, the most consistent metabolic differences again

Table 2 Mean (SE) differences in cognitive functions between slowly and rapidly progressive groups of patients with Alzheimer's disease

\begin{tabular}{lll}
\hline & $\begin{array}{l}\text { Slow } \\
\text { progression } \\
(n=13)\end{array}$ & $\begin{array}{l}\text { Rapid } \\
\text { progression } \\
(n=8)\end{array}$ \\
\hline Global neuropsychological & & \\
functions: & & \\
Verbal IQ (WAIS-R) & $88(3 \cdot 6)$ & $80(5 \cdot 4)$ \\
Performance IQ (WAIS-R) & $79(4 \cdot 0)$ & $73(4 \cdot 1)$ \\
Full scale IQ (WAIS-R) & $84(3 \cdot 3)$ & $76(4 \cdot 7)$ \\
Memory scale (WMS) & $76(3 \cdot 1)$ & $67(4 \cdot 1)$ \\
Tests associated with verbal & & \\
functions: & $4 \cdot 2(0 \cdot 4)$ & $3 \cdot 3(0 \cdot 9)$ \\
Rey verbal learning & $11(1 \cdot 0)$ & $11(1 \cdot 7)$ \\
Sentence memory & & \\
Tests associated with visuospatial & & \\
functions: & $19(3 \cdot 5)$ & $14(4 \cdot 7)$ \\
Rey Osterrieth figure & $3 \cdot 7(0 \cdot 4)$ & $3 \cdot 6(0 \cdot 6)$ \\
Benton visual retention & $11(0 \cdot 9)$ & $10(0 \cdot 9)$ \\
Street map & $2 \cdot 7(1 \cdot 0)$ & $2 \cdot 6(0 \cdot 6)$ \\
Mosaics & & \\
Tests associated with executive & & \\
functions: & $207(4)$ & $145(37)^{\star}$ \\
Ego state inventory & $8 \cdot 7(0 \cdot 9)$ & $5 \cdot 6(1 \cdot 5)^{\star}$ \\
Word fluency & &
\end{tabular}

WAIS-R = Wechsler adult intelligence scale, revised; WMS =

Wechsler memory scale.
${ }^{\star} p<0.05$ for group differences. 
Table 3 Linear correlation of progression rate of Alzheimer's disease with neuropsychological tests scores in 21 patients

\begin{tabular}{lc}
\hline & $\begin{array}{l}\text { Pearson's } \\
\text { correlation } \\
\text { coefficient }\end{array}$ \\
\hline Global neuropsychological functions: & -0.39 \\
Verbal IQ (WAIS-R) & -0.27 \\
Performance IQ (WAIS-R) & -0.40 \\
Full scale IQ (WAIS-R) & -0.41 \\
MQ (WMS) & -0.24 \\
Tests associated with verbal functions: & -0.08 \\
Rey verbal learning & -0.33 \\
Sentence memory & 0.07 \\
Tests associated with visuospatial functions: \\
Rey Osterrieth figure & -0.33 \\
Benton visual retention & 0.05 \\
Street map & $-0.53^{\star}$ \\
Mosaics & $-0.74^{\star \star}$ \\
Tests associated with executive functions: \\
Word fluency & $-0.44^{\star}$ \\
Ego state inventory & \\
Mental control (WMS) & \\
\hline WAIS-R = Wechsler adult intelligence scale, revised; WMS $=$ \\
Wechsler memory scale.
\end{tabular}

Table 4 Mean (SE) differences in regional cerebral glucose metabolism between slowly and rapidly progressive groups of patients with Alzheimer's disease

\begin{tabular}{|c|c|c|}
\hline Brain region & $\begin{array}{l}\text { Slow } \\
\text { progresion } \\
(n=13)\end{array}$ & $\begin{array}{l}\text { Rapid } \\
\text { progression } \\
(n=8)\end{array}$ \\
\hline $\begin{array}{l}\text { Frontal cortex: } \\
\text { Inferior } \\
\text { Middle } \\
\text { Superior anterior } \\
\text { Superior mesial } \\
\text { Superior posterior }\end{array}$ & $\begin{array}{l}2 \cdot 7(0 \cdot 3) \\
3 \cdot 0(0 \cdot 2) \\
2 \cdot 7(0 \cdot 2) \\
2 \cdot 9(0 \cdot 2) \\
2 \cdot 5(0 \cdot 2)\end{array}$ & $\begin{array}{l}2 \cdot 5(0 \cdot 2) \\
2 \cdot 5(0 \cdot 2) \\
2 \cdot 3(0 \cdot 2) \\
2 \cdot 3(0 \cdot 1)^{\star} \\
2 \cdot 0(0 \cdot 1)^{\star}\end{array}$ \\
\hline $\begin{array}{l}\text { Temporal cortex: } \\
\text { Inferior } \\
\text { Superior }\end{array}$ & $\begin{array}{l}2 \cdot 4(0 \cdot 2) \\
2 \cdot 5(0.2)\end{array}$ & $\begin{array}{l}2 \cdot 3(0.2) \\
2 \cdot 5(0.2)\end{array}$ \\
\hline $\begin{array}{l}\text { Parietal cortex: } \\
\text { Inferior } \\
\text { Superior } \\
\text { Occipital cortex }\end{array}$ & $\begin{array}{l}2 \cdot 4(0 \cdot 2) \\
2 \cdot 7(0 \cdot 2) \\
2 \cdot 8(0 \cdot 2)\end{array}$ & $\begin{array}{l}2 \cdot 2(0 \cdot 2) \\
2 \cdot 3(0 \cdot 1) \\
2 \cdot 8(0 \cdot 3)\end{array}$ \\
\hline $\begin{array}{l}\text { Subcortical regions: } \\
\text { Caudate } \\
\text { Lenticular nuclei } \\
\text { Thalamus }\end{array}$ & $\begin{array}{l}2 \cdot 8(0 \cdot 1) \\
3 \cdot 2(0 \cdot 2) \\
2.9(0 \cdot 2)\end{array}$ & $\begin{array}{l}3.0(0 \cdot 3) \\
3 \cdot 2(0.6) \\
3 \cdot 0(0 \cdot 2)\end{array}$ \\
\hline
\end{tabular}

${ }^{\star} p<0.05$ for group differences.

Table 5 Linear correlation of progression rate of Alzheimer's disease with regional cerebral glucose metabolism

\begin{tabular}{ll}
\hline Brain region & $\begin{array}{l}\text { Pearson's } \\
\text { correlation } \\
\text { coefficient }\end{array}$ \\
\hline Frontal cortex: & -0.21 \\
Inferior & -0.27 \\
Middle & -0.42 \\
Superior anterior & $-0.48^{\star}$ \\
Superior mesial & $-0.49^{\star}$ \\
Superior posterior & 0.04 \\
Temporal cortex: & 0.06 \\
Inferior & \\
Superior & 0.09 \\
Parietal cortex: & -0.23 \\
Inferior & 0.08 \\
Superior & 0.13 \\
Occipital cortex & 0.19 \\
Subcortical regions: & 0.06 \\
Caudate & \\
Lenticular nuclei & \\
Thalamus & \\
\hline${ }^{\star}$ < < 0.05. &
\end{tabular}

emerged in the superior frontal regions bilaterally (figure).

\section{Discussion}

Characteristic differences in neuropsychological patterns and patterns of glucose metabo- lism were found in patients with probable Alzheimer's disease segregated on the basis of rate of progression of symptoms. Although the degree of parietotemporal cortical abnormality was indistinguishable, the more rapidly deteriorating group had significantly more frontal lobe dysfunction as shown both by performance on neuropsychological tests and by regional cerebral glucose metabolism. Although differences in progression rate between patients with distinctive patterns of cognitive dysfunction have recently been reported, only visuoconstructional and lexicalsemantic language abilities were examined, and no measurements of frontal lobe function were included. ${ }^{9}$

Rates of symptom deterioration ranged widely in patients admitted to this study but failed to correlate with any of the demographic variables considered, such as age at symptom onset or educational level. In contrast, earlier reports suggested that younger patients with Alzheimer's dementia tend to have a more rapid decline in overall intellectual function. ${ }^{1}$ More recent studies using a longitudinal approach tend to support the present findings, revealing no significant relation between the rate of clinical deterioration and age at symptom onset. ${ }^{35-37}$ However, the possibility cannot totally be excluded that patients in the rapidly progressing group, while fulfilling current diagnostic criteria for Alzheimer's disease, actually suffered from some other dementing disorder.

A single measurement may be an imperfect index of rate of change in symptoms over an extended period due to the relative lack of linearity in the progression of symptoms, but it is striking to note that the average loss of 12 points a year on the dementia rating scale found in the present group of 21 subjects closely corresponds to recent observations using the dementia rating scale over a two year period in Alzheimer's patients. ${ }^{38}$

PET-FDG studies evaluating Alzheimer's disease have focused on inter individual variations in regional patterns of metabolic dysfunction. ${ }^{81439}$ Though some earlier investigations emphasised hemispheric asymmetry, ${ }^{12} 40$ more recent studies have often focused on anterior or posterior changes. ${ }^{1314}$ Consistent with the present data, frontal hypometabolism was associated with greater impairment in attentional tests and verbal fluency. ${ }^{13}{ }^{14}$ These differences in focal abnormalities could reflect different stages of disease. ${ }^{4142}$ While the parietal regions are most affected in milder cases, frontal and anterior temporal cortical regions seem increasingly hypometabolic in more advanced patients. ${ }^{4142}$ Nevertheless, patients in both of our groups showed equivalent degrees of parietal metabolic dysfunction and posterior neuropsychological disability. Since this was true in both relative and absolute terms (patients with fast progression had consistently lower frontal glucose metabolic values and lower scores on executive function tests) it would seem more likely that we are dealing with two different subgroups rather than different stages of illness in the same 


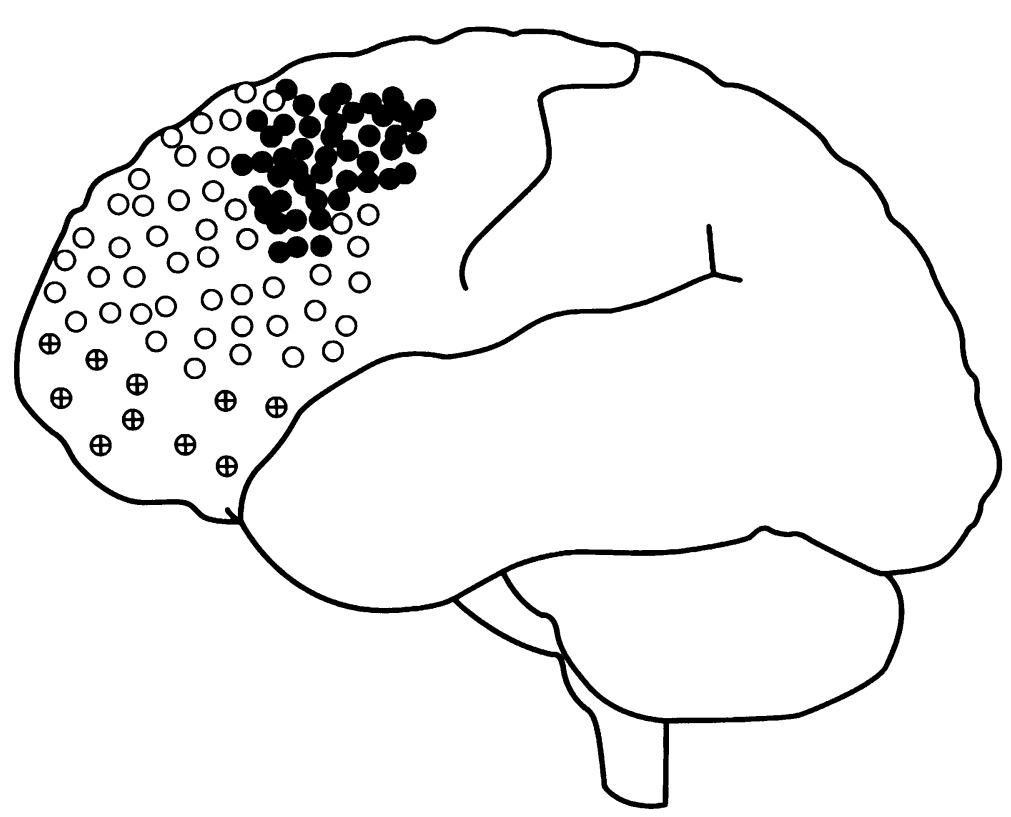

Figure Regional differences in glucose metabolism in rapidly and slowly progressive Alzheimer's disease. Scores calculated as $(r G M R)_{s}-(r G M R)_{R} /\left((r G M R)_{s}+\right.$ $\left.(r G M R)_{R} / 2\right)$. Closed circles are for scores $>0 \cdot 2$, open circles for $0 \cdot 1$ to $0 \cdot 2$, and hatched circles for $<0 \cdot 1$.
10 Becker JT. Working memory and secondary memory deficits in Alzheimer's disease. F Clin Exp Neuropsychol 1988; 10:739-53.

11 Foster NL, Chase TN, Mansi L, et al. Cortical abnormalities in Alzheimer's disease. Ann Neurol 1984; 16:649-54.

12 Friedland RP, Budinger TF, Koss E, Ober BA. Alzheimer's disease: anterior-posterior and lateral hemisphere alterations in cortical glucose utilization. Neurosci Lett 1985;53:235-40.

13 Chase TN, Burrows GH, Mohr E. Cortical utilization patterns in primary degenerative dementias of the anterior and posterior type. Arch Gerontol Geriatr 1987; 6:289-97.

14 Haxby JV, Grady CL, Koss E, et al. Heterogeneous anteriorposterior metabolic patterns in dementia of the Alzheimer type. Neurology 1988;38:1853-63.

15 Abely X, Guirard P, Dechosal J. Alzheimer of acute onset. Annall Medicopsychologiques 1958;116:294-9.

16 Newton RD. Identity of Alzheimer's disease and senile dementia and their relation to senility. $\mathcal{f}$ Ment $S c i$ 1948;94:225-49.

17 Mann UM, Mohr E, Chase TN. Rapidly progressive Alzheimer's disease. Lancet 1989;ii:229.

18 American Psychiatric Association. Diagnostic and statistical manual of mental disorders. 3rd ed, revised, Washington DC: American Psychiatric Association, 1987.

19 McKhann G, Drachman D, Folstein M, Katzman R, Price $D$, Stadlan EM. Clinical diagnosis of Alzheimer's disease: report of the NINCDS-ADRDA work group under the auspices of department of health and human services task force on Alzheimer's disease. Neurology 1984;34: 939-44.

20 Mattis S. Mental status examination for organic mental syndrome in the elderly. In: Bellack L, Karasu TB eds. Geriatric psychiatry. New York: Grune and Stratton, 1976:77-121.

21 Wechsler D. Wechsler adult intelligence scale-revised. New York: The Psychological Corporation, 1981.

22 Wechsler D, Stone CP. Wechsler memory scale. New York: The Psychological Corporation, 1945 .

23 Mohr E, Bruno G, Foster N, et al. GABA-agonist therapy for Alzheimer's disease. Clin Neuropharm 1986;9: for Alzh.

group. using a longitudinal design, may have implications for the development of more effective treatments for Alzheimer's disease. Conceivably, the limited success of current transmitter replacement strategies could, in part, reflect heterogeneity within the target population of patients with clinically diagnosed Alzheimer's disease. Differences in regional cerebral involvement may reflect differences in transmitter system involvement, which in turn could affect the response of symptoms to treatment and emphasise the need to choose the treatment most suitable for each individual patient.

We thank Dr Howard Burrows for designing the analysis program for PET images and Tim Collins for his technical help in computer programming.

$1 \mathrm{McDonald}$ C. Clinical heterogeneity in senile dementia. $\mathrm{Br}$ P Psychiatry 1969;115:267-71.

2 Mayeux R, Stern Y, Spanton S. Heterogeneity in dementia of Alzheimer's type: evidence of subgroups. Neurology 1985;35:453-61.

3 Selzer B, Sherwin I. A comparison of clinical features in early-and late-onset primary degenerative dementia. One entity or two? Arch Neurol 1983;40:143-6.

4 Filley CM, Kelly J, Heaton RK. Neuropsychologic feature of early and late-onset Alzheimer's disease. Arch Neurol 1986;43:574-6.

5 Zubenko GS, Moossy J, Martinez AJ, Rao GR, Kopp U, Hanin I. A brain regional analysis of morphologic and cholinergic abnormalities in Alzheimer's disease. Arch Neurol 1989;46:634-8.

6 Bondareff W, Mountioy CQ, Roth M, Rossor MN, Iversen LL, Reynolds GP. Age and histopathologic heterogeneity in Alzheimer's disease. Arch Gen Psychiatry 1987;44: in Alzheir.

7 Martin A, Brouwers P, Lalonde F, et al. Towards a behavioral typology of Alzheimer's patients. $\mathcal{f}$ Clin Exp Neuropsychol 1986;5:594-610.

8 Foster NL, Chase TN, Fedio P, Patronas NJ, Brooks RA. Alzheimer's disease: focal cortical changes shown by positron emission tomography. Neurology 1983;33: 961-5.

9 Becker JT, Huff FJ, Nebes RD, Holland A, Boller F Neuropsychological function in Alzheimer's disease. Pattern of impairment and rates of progression. Arch Neurol 1988;45:263-8.
24 Woodcock BWL, Johnson BW. Woodcock-fohnson psychoeducational battery. Boston: Teaching Resources Corporation, 1972.

25 Rey A. L'examen psychologique dans le cas d'encephalopathie traumatique. Arch Psychol 1941;28:286-340.

26 Osterrieth PA. Le test de copie d'une figure complexe: contribution l'étude de la perception et de la memoire. Arch Psychologie 1944;30:206-356.

27 Benton AL, Spreen O, Hamsher KS. Contributions to neuropsychological assessment: clinical manual. New York: Oxford University Press, 1983.

28 Money JA. Standardized road map of direction sense. San Rafael, California: Academic Therapy Publications, Rafael,

29 Brouwers P, Cox C, Martin A, Chase TN, Fedio P. ton's and Alzheimer's dementia. Arch Neurol 1984; 41:1073-6. Iowa City: University of Iowa, 1976

31 McCarley DG. Ego state inventory Chicago: Stolting Company, 1975 .

32 Brooks RA. Alternate formula for glucose utilisation using labelled deoxyglucose. $7 \mathrm{Nucl} \mathrm{Med} \mathrm{1982;23:538-9.}$

33 Bright DS. A LISP based image analysis system with applications to microscopy. I Microscopy 1987;148: 51-87.

34 Dixon WJ, Brown MB, Engelman L, et al. BMDP statistical software. Los Angeles: University of California, 1985.

35 Thal LJ, Grundman M, Klauber MR. Dementia: Caracteristics of a referral population and factors associated teristics of a referral population and factors annual change of mental status score in four independent studies of patients

37 Ortof E, Crystal HA. Rate of progression of Alzheimer's disease. $\mathcal{F} A G S$ 1989;37:511-4.

38 Salmon DP, Thal LJ, Butters N, Heindel WC. Longitudinal evaluation of dementia of the Alzheimer type: comparison of 3 standardized mental status examinations. Neurology 1990;40:1225-30.

39 Chase TN, Foster NL, Fedio P, Brooks R, Mansi L, DiChiro G. Regional cortical dysfunction in Alzheimer's Ann Neurol 1984;15[suppl]:170-4.

40 Grady CL, Haxby JV, Schlageter NL, Berg G, Rapoport SI. Stability of metabolic and neuropsychological asymmetries in dementia of the Alzheimer's type. Neurology tries in dementia.

41 Haxby JV, Grady CL, Friedland RP, Rapoport SI. Neocortical metabolic abnormalities precede nonmemory cogniical metabolic abnormalities precede nonmemory cognitive impairments in early dementia of the Alzheimer type:
longitudinal confirmation. $f$ Neural Transm 1987; longitudinal con

42 Chase TN, Foster NL. Alterations in local cortical glucose metabolism in Alzheimer's disease. Drugs Dis 1984;1: 175-80. Differential perceptual spatial impairment in Hunting-

30 Benton AL, Hamsher KS. Multilingual aphasia examination.

36 Katzman R, Brown T, Thal LJ, et al. Comparison of rate of disease as determined by positron emission tomography. 